Available online at www.eccomasproceedia.org

Eccomas Proceedia COMPDYN (2021) 4283-4293

ECCOMAS

Proceedia
COMPDYN 2021

$8^{\text {th }}$ ECCOMAS Thematic Conference on Computational Methods in Structural Dynamics and Earthquake Engineering M. Papadrakakis, M. Fragiadakis (eds.) Streamed from Athens, Greece, 28 - 30 June 2021

\title{
FLEXURAL PERFORMANCE OF CONCRETE BEAMS UNDER CYCLIC LOADING
}

\author{
Waseem Khan ${ }^{1}$, Saleem Akhtar ${ }^{2}$, Aruna Rawat ${ }^{3}$ and Anindya Basu ${ }^{4}$ \\ ${ }^{1}$ Research Scholar, Department of Civil Engineering, University Institute of Technology (UIT), \\ RGPV, Bhopal - 462 033, Madhya Pradesh, India. \\ e-mail:wkrgpv@gmail.com \\ ${ }^{2}$ Professor, Department of Civil Engineering, University Institute of Technology (UIT), RGPV, Bho- \\ pal - 462 033, Madhya Pradesh, India. \\ e-mail: sargpv@gmail.com \\ ${ }^{3}$ Assistant Professor, Department of Civil Engineering, University Institute of Technology (UIT), \\ RGPV, Bhopal - 462 033, Madhya Pradesh, India. \\ e-mail: augupta2001@gmail.com \\ ${ }^{4}$ UGC-Assistant Professor, School of Pharmaceutical Science Engineering, RGPV, Bhopal - 462 033, \\ Madhya Pradesh, India. \\ e-mail: anindya@rgtu.net
}

\begin{abstract}
A large portion of the civil concrete structures get damaged during an earthquake event, hence structures required some substitution and restoration. In the present study, the flexural performance of concrete beams under variation of magnitude on cyclic loading is investigated. ABAQUS finite element (FE) program is used to numerically perform a parametric study for five different depths of beams varying from 250 to $750 \mathrm{~mm}$ under cyclic loading. The finite element (FE) beams are modeled using Concrete Damaged Plasticity model (CDP) model. The effect of beam depth on the flexural strength of concrete beam is investigated. The effect of cyclic loading on strength and deformation behavior, yielding, ultimate, failure strengths as well as on displacements are evaluated. The load-deflection curves are obtained for different beams and are compared to static loading.
\end{abstract}

Keywords: Concrete damage plasticity, Cyclic load, Finite element model, Flexural strength. 


\section{INTRODUCTION}

A large portion of the civil concrete structures get damaged during an earthquake event, hence structures required some substitution and restoration. A wide range of tests have been conducted to understand the effect of cyclic load on reinforced concrete structural members during the earthquake. The failure of reinforced concrete $(\mathrm{RC})$ beam is a progressive process of micro crack initiation and propagation leading to micro cracks that grow to a stage in which failure occurs. Under the repeated cyclic loading, the mechanical properties of concrete changes, thus strain increases permanently, whereas the modulus of elasticity decreases. In the case of a reinforcing bar, cyclic load causes micro- cracking that initiates a stress concentration at the bar surface. As the cyclic stress continues, the crack propagates, leading to sudden fracture crack that grow to a stage in which failure occurs.

In the present study, the flexural performance of three-dimensional nonlinear RC beams under cyclic and static loading are analyzed using concrete damaged-plasticity (CDP) [10] model available in the software ABAQUS [11].

\subsection{Furthermore work has been done on cyclic load}

Yonezawa et al., 2020 [1] investigated the effect of cyclic load on welded joints and measured the residual stress at the ultrasonic impact treatment groove using X-ray diffraction method. Ftaikhan et al., 2019 [2] studied the effect of FRP and CFRP bar embedded in RC frame subjected to dynamic loading using ABAQUS and ARCS3D finite element softwares. Tsutsumi et al., 2019 [3] analyzed the cyclic response of steel bridged pier and also evaluate the load-carrying capacity of steel bridge pier. Jamadin et al., 2019 [4] investigated the natural frequencies, mode shapes and damping ratios for bridge reinforced concrete deck slabs under cyclic and static loads. Koltsida et al., 2019 [5] tested brick masonry prisms under compressive cyclic loading at different maximum stress levels until failure and developed three mathematical equations to predict the three characteristic stages of fatigue of brick masonry. Haris and Roszevàk, 2019 [6] analyzed RC frame joint under monotonic increasing quasi-static and cyclic changing loads. Xiao et al., 2018 [7] studied the effect change in loading rate on the dynamic behavior of reinforced concrete beams under cyclic loading. Harba and Abdulridha, 2017 [8] studied the effect of five different cyclic loads on RC hunched beam. Parvez and Foster, 2015 [9] showed that steel-fiber-reinforced concrete under constant amplitude cyclic loading has low smaller deflections and smaller crack widths than that of control specimens and reducing the stress level in the tensile reinforcement.

Based on the observations from the literature review and gaps, the following are the objectives of the present work:

(i) A parametric study of five different depths of rectangular beams (having width $200 \mathrm{~mm}$ and length $1500 \mathrm{~mm}$ constant) varying from 250 to $750 \mathrm{~mm}$ under static and cyclic loading is carried out.

(ii) To study the effect of increasing depth of beam on load-deflection curve of RC beams under cyclic loading and also compared it with static loading.

(iii)To determine plastic strain, principal stress and mid span deflection under cyclic and static loadings.

\section{PROPOSED METHODOLOGY}

A rectangular RC beam having constant width $200 \mathrm{~mm}$ and length $1500 \mathrm{~mm}$. the beam is having varying depths of $250 \mathrm{~mm}, 350 \mathrm{~mm}, 500 \mathrm{~mm}, 600 \mathrm{~mm}$ and $750 \mathrm{~mm}$ is analysed as given in Table 1. A FE element model of RC beam using C3D8 brick element has been created and analysed in FE software package ABAQUS. The material properties of RC beam are 
given in Table 2. The nonlinear behavior of concrete is modeled using CDP model [10] can define the compression load behavior and tension load behavior. Figure 1 shows the cyclic loading considered in the present study having load of $2000 \mathrm{~N}$ to $3000 \mathrm{~N}$. Figure 2 shows the FE model of RC beam. The steel reinforcement is embedded in to the concrete beam. The mesh size adopted in the present work is $50 \mathrm{~mm}$.

\begin{tabular}{ccccc}
\hline Beam Designation & $\begin{array}{c}\text { Width } \\
(\mathrm{mm})\end{array}$ & $\begin{array}{c}\text { Depth } \\
(\mathrm{mm})\end{array}$ & $\begin{array}{c}\text { Effective length } \\
(\mathrm{mm})\end{array}$ & $\begin{array}{c}\text { Width/Depth } \\
\text { ratio }\end{array}$ \\
\hline B-1 & 200 & 250 & 1500 & 0.8 \\
B-2 & 200 & 350 & 1500 & 0.57 \\
B-3 & 200 & 500 & 1500 & 0.4 \\
B-4 & 200 & 600 & 1500 & 0.33 \\
B-5 & 200 & 750 & 1500 & 0.27 \\
\hline
\end{tabular}

Table 1: Beam dimensions.

\begin{tabular}{|c|c|c|c|c|c|c|c|c|}
\hline Beam & Concrete mix & $\begin{array}{c}f_{\text {ck }} \\
(\mathrm{Mpa})\end{array}$ & $\begin{array}{c}f_{\mathrm{tk}} \\
(\mathrm{MPa})\end{array}$ & $\begin{array}{c}E_{\mathrm{c}} \\
(\mathrm{MPa})\end{array}$ & $\begin{array}{c}E_{\mathrm{s}} \\
(\mathrm{GPa})\end{array}$ & $\begin{array}{l}\text { Main Rein- } \\
\text { forcement }\end{array}$ & Stirrups & $\begin{array}{c}\text { Effective } \\
\text { cover }\end{array}$ \\
\hline $\begin{array}{l}\text { B-1 to } \\
\text { B-5 }\end{array}$ & M60 & 61.8 & 4.6 & $\begin{array}{c}39306 \\
.49\end{array}$ & 2.1 & $\begin{array}{c}\text { 4\#20 mm } \\
\text { dia. }\end{array}$ & $\begin{array}{c}10 \mathrm{~mm} \\
\text { dia.@ } \\
140 \mathrm{~mm} \\
\mathrm{c} / \mathrm{c}\end{array}$ & $20 \mathrm{~mm}$ \\
\hline
\end{tabular}

Table 2: Material properties.

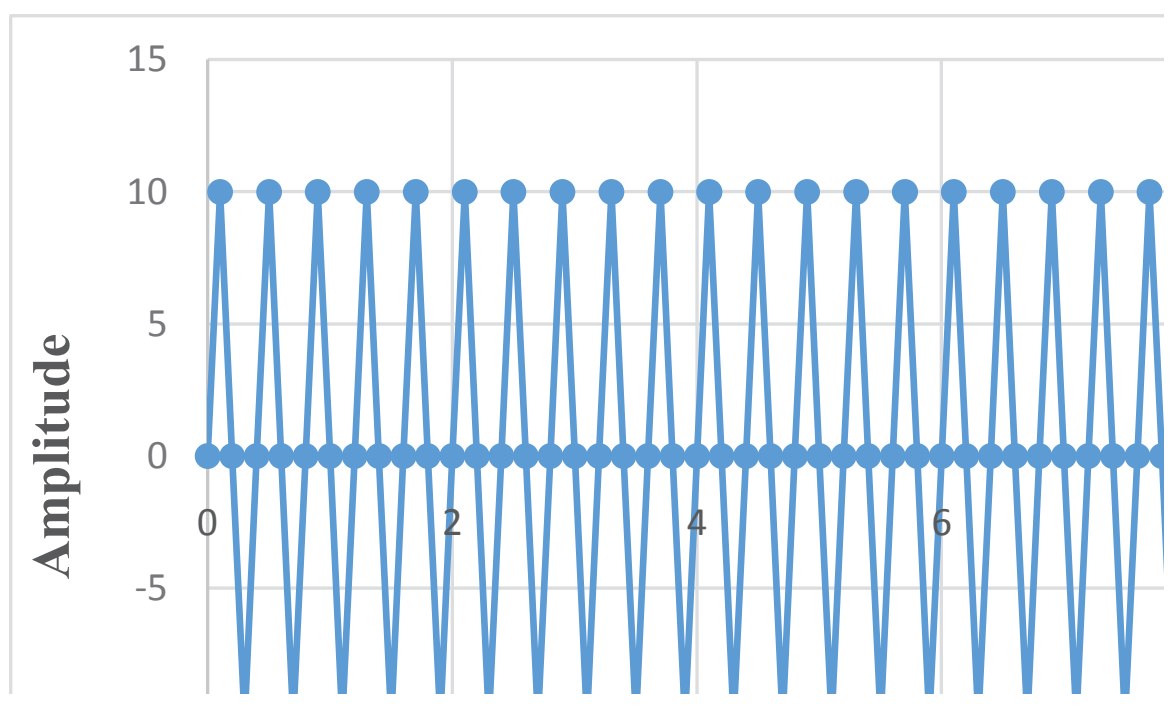

Figure 1: Cyclic loading. 


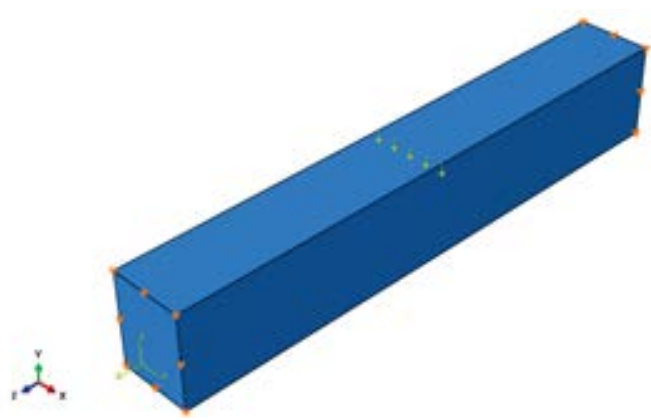

Geometry

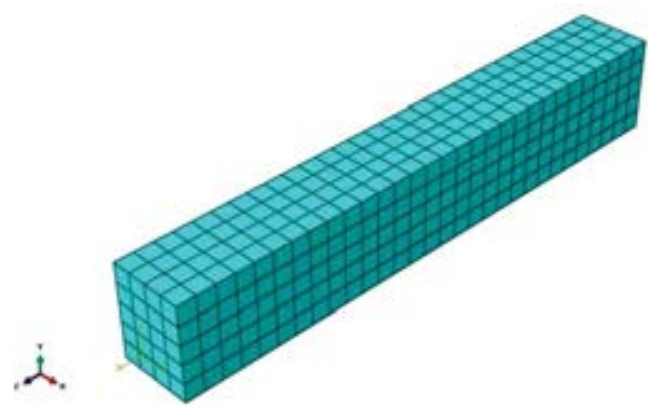

Meshing

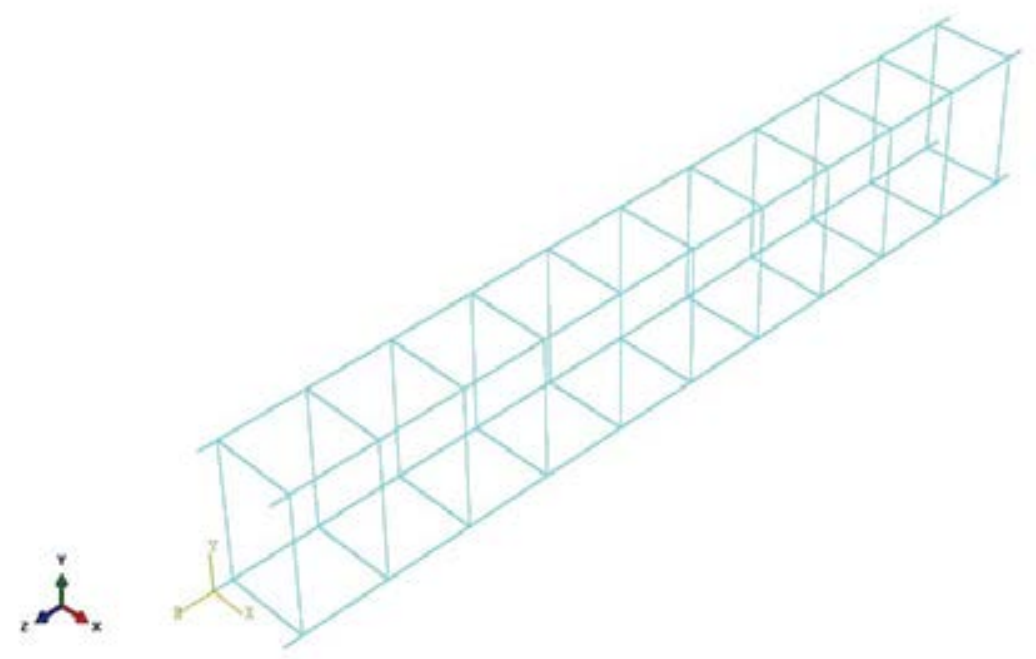

Steel reinforcement

Figure 2: FE model of RC beam.

\section{RESULTS AND DISCUSSIONS}

Total five RC beams (B-1 to B-5) has been analyzed. The results prevail to the objectives of the study are presented and discussed in this section. Table 3 gives the initial plastic load and deflection for B-1 to B-5 beams under cyclic loading. Table 4 gives the load and deflection values under static loading of $50000 \mathrm{~N}$. Figure 3 shows the load-deflection curves for B-1 to B-5 RC beams under cyclic loading. It can be observed that as the depth of beam increases the deflection decrease in the beams. Figure 4 shows the load-deflection curve for the RC beams under static loading. It can be observed from the figure that as the depth of beam increases the deflection reduces. It is observed that deflection is less in B-5 beam having a depth of $750 \mathrm{~mm}$.

\begin{tabular}{ccc}
\hline Beam Designation & $\begin{array}{c}\text { Initial Plastic Load } \\
(\mathrm{N})\end{array}$ & $\begin{array}{c}\text { Initial Plastic deflection } \\
(\mathrm{mm})\end{array}$ \\
\hline B-1 & 19987.2 & 0.26 \\
B-2 & 24932.6 & 0.15 \\
B-3 & 29768.3 & 0.05 \\
B-4 & 29586.4 & 0.03 \\
B-5 & 25000 & 0.02 \\
\hline
\end{tabular}

Table 3: Initial plastic load and deflection under cyclic loading. 


\begin{tabular}{ccc}
\hline Beam Designation & Load $(\mathrm{N})$ & Deflection $(\mathrm{mm})$ \\
\hline B-1 & 50000 & 1.42 \\
B-2 & 50000 & 0.70 \\
B-3 & 50000 & 0.50 \\
B-4 & 50000 & 0.47 \\
B-5 & 50000 & 0.45 \\
\hline
\end{tabular}

Table 4: Load and deflection under static load.

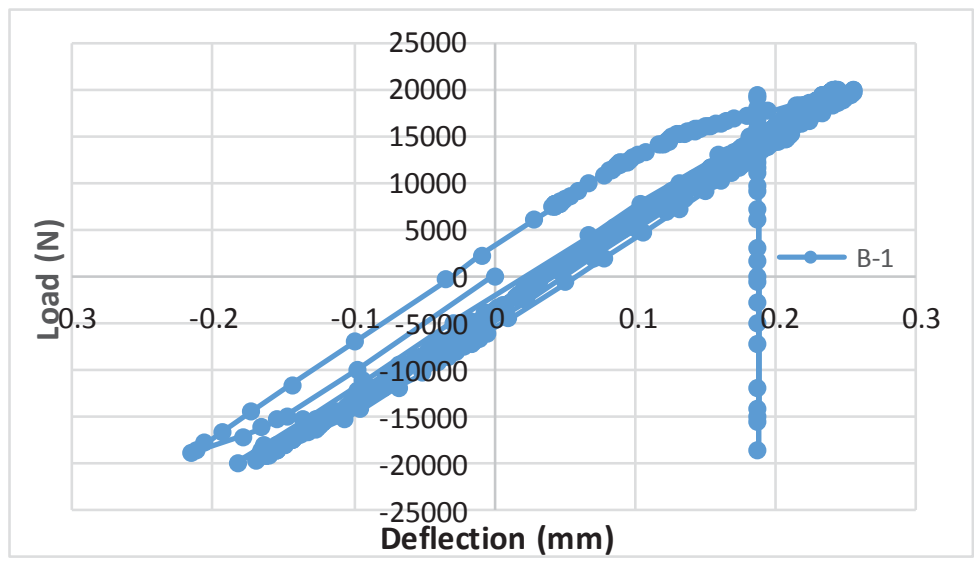

(a) B-1 RC beam

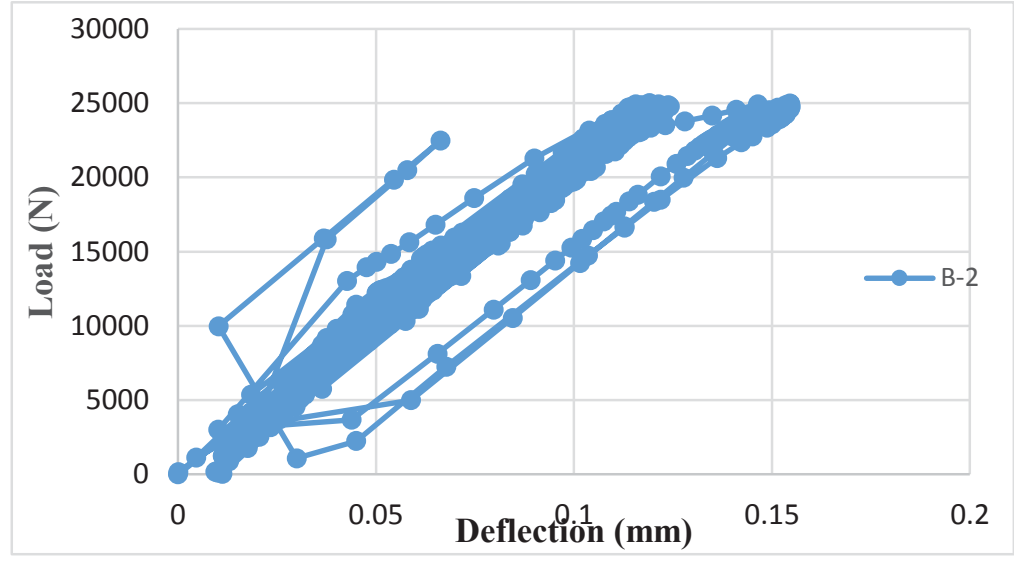

(b) B-2 RC beam 


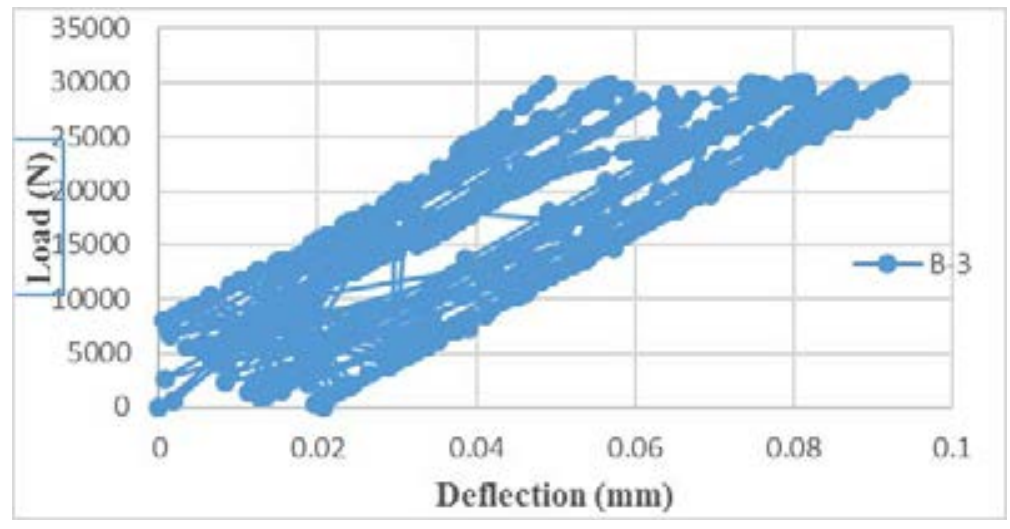

(c) B-3 RC beam

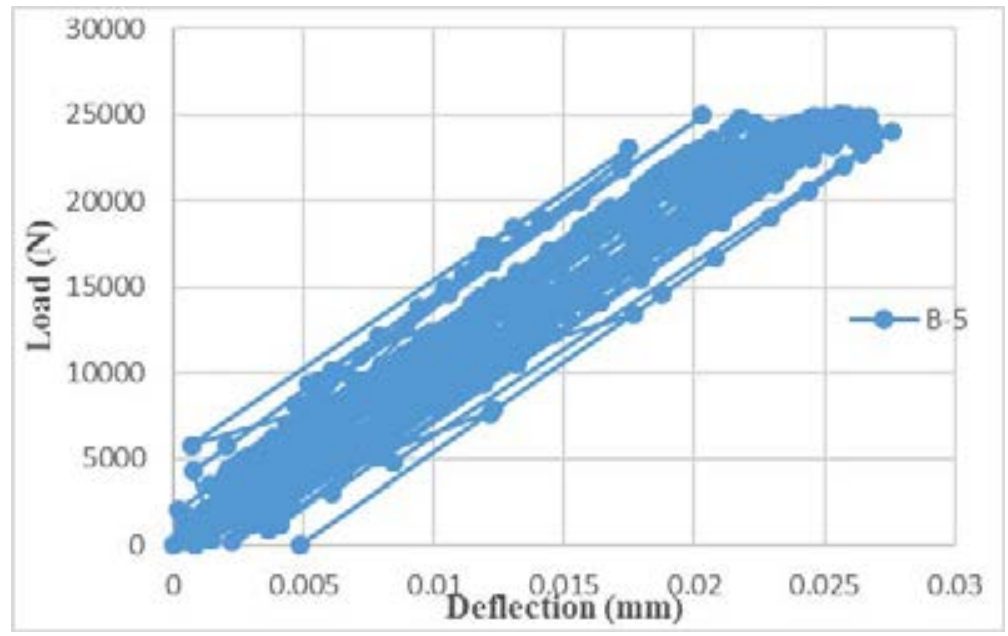

(d) B-4 RC beam

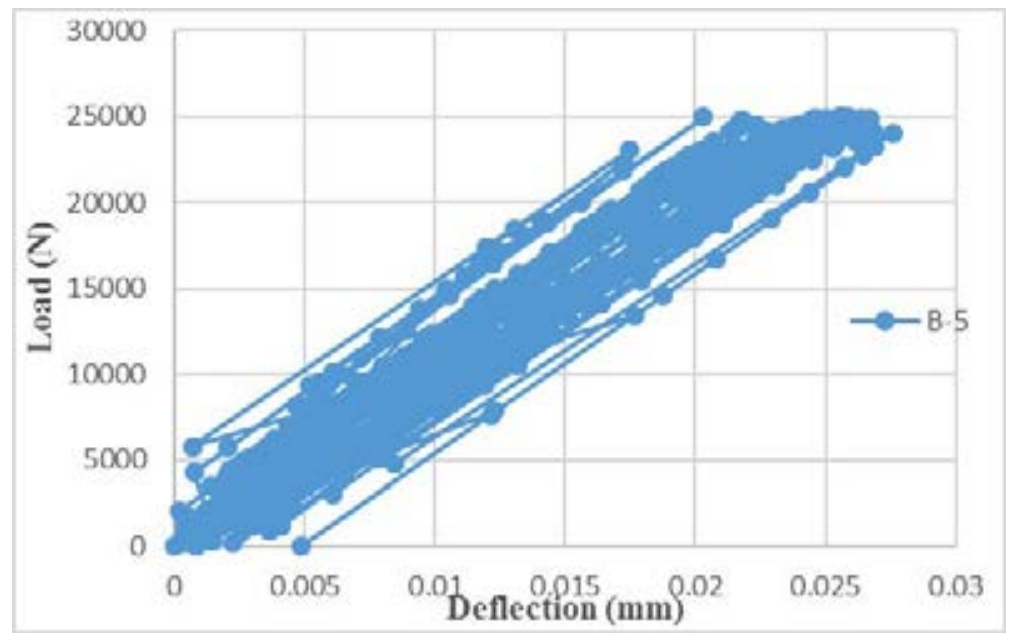

(e) B-5 RC beam

Figure 3: Load-deflection curves RC beams under cyclic loading. 


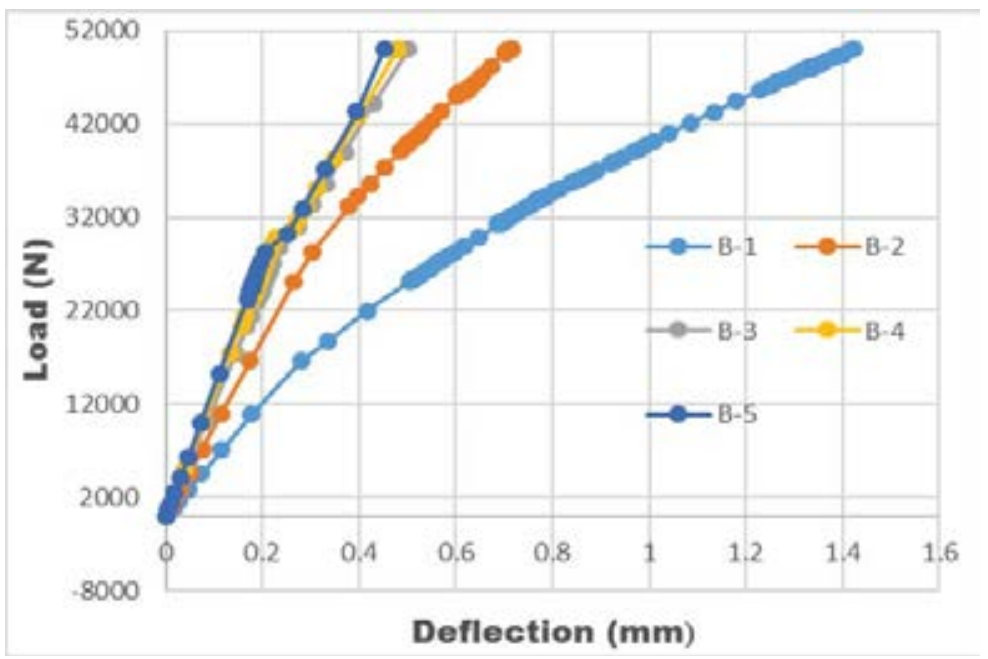

Figure 4: Load-deflection curves RC beams under static loading.

B-1

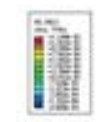

\section{ii}
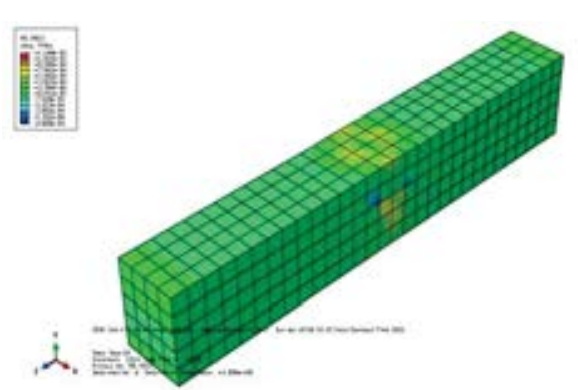

B-2

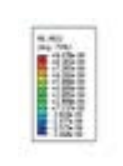

B-2

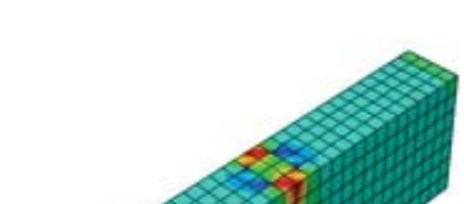

之.
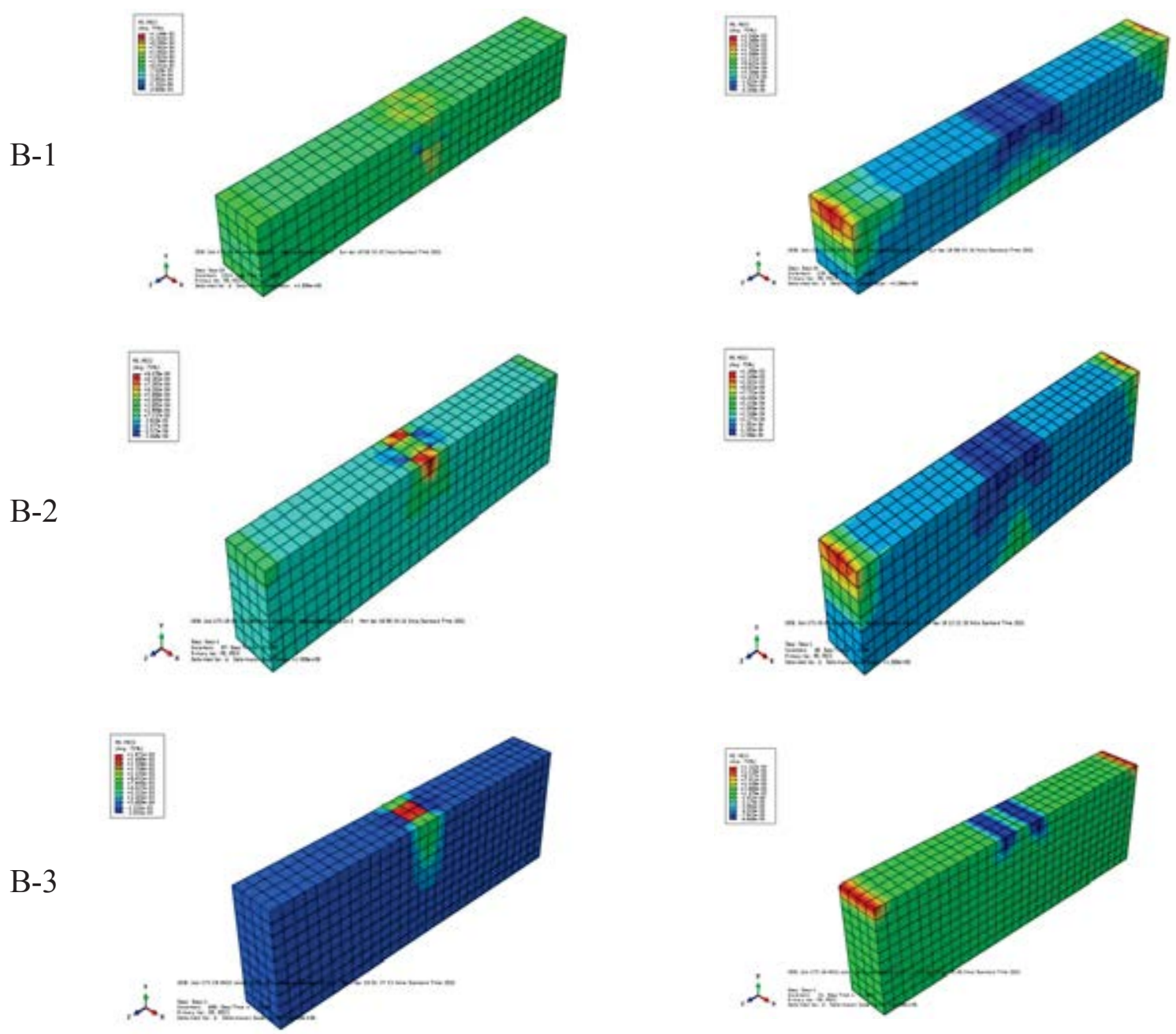


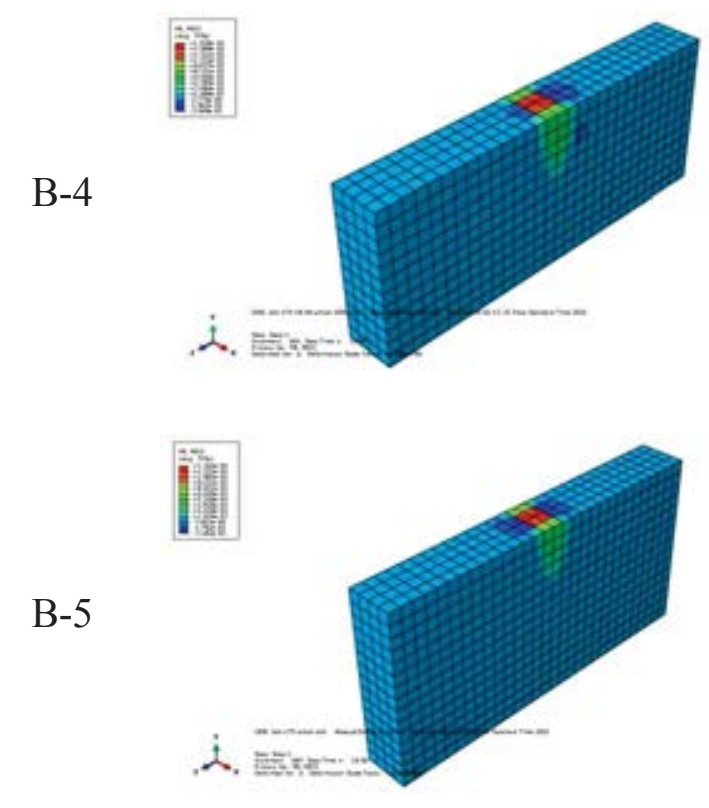

Cyclic loading
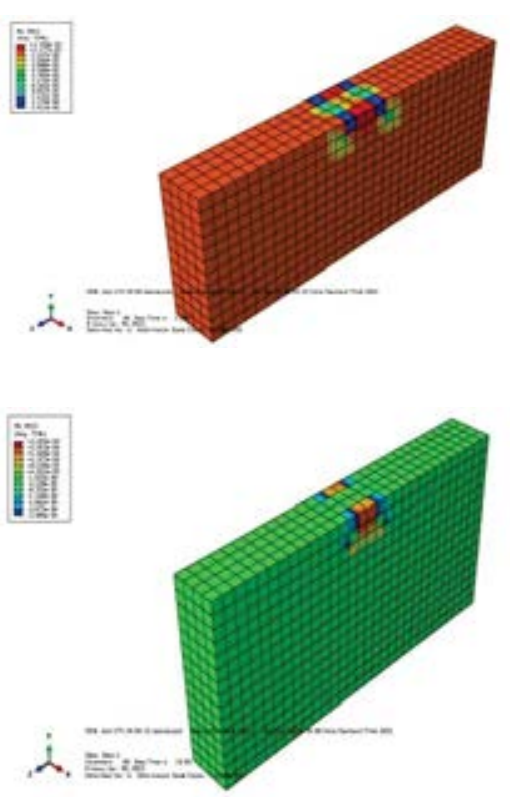

Static loading

Figure 5: Plastic strain for RC beams under cyclic and static loading.

B-1
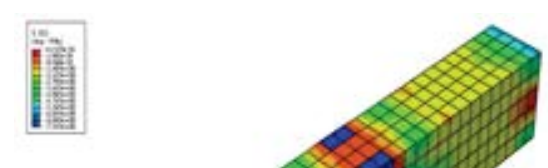

¿.

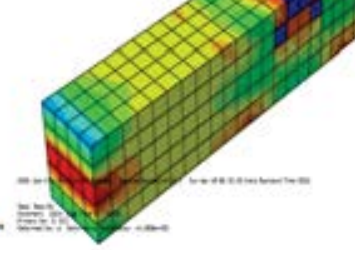

\section{ii}

B-2

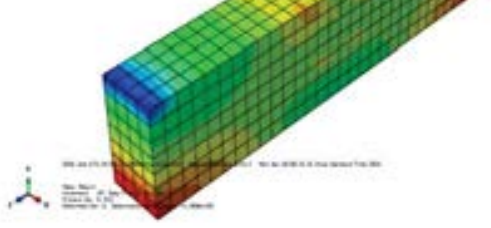

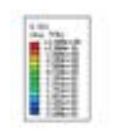
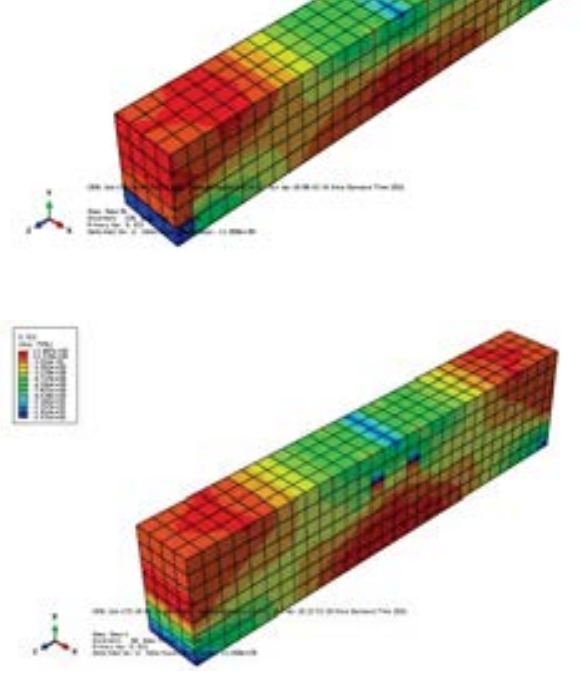
B-3

\section{iil

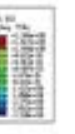

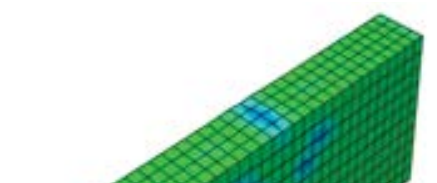
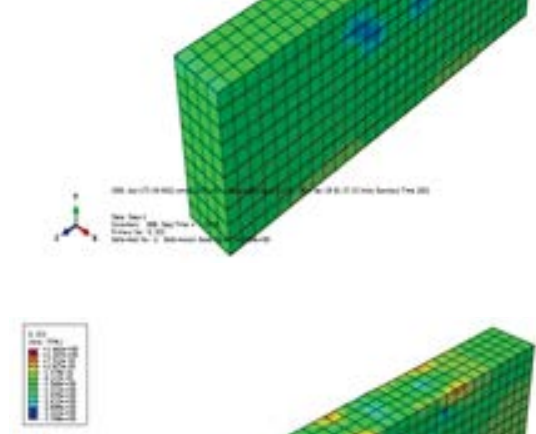

B-4

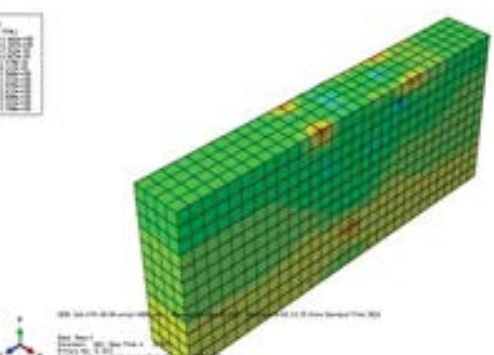

B-5

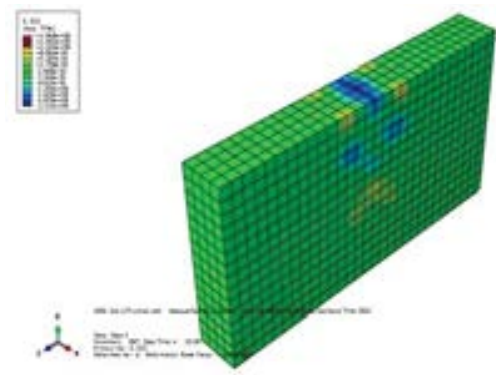

Cyclic loading
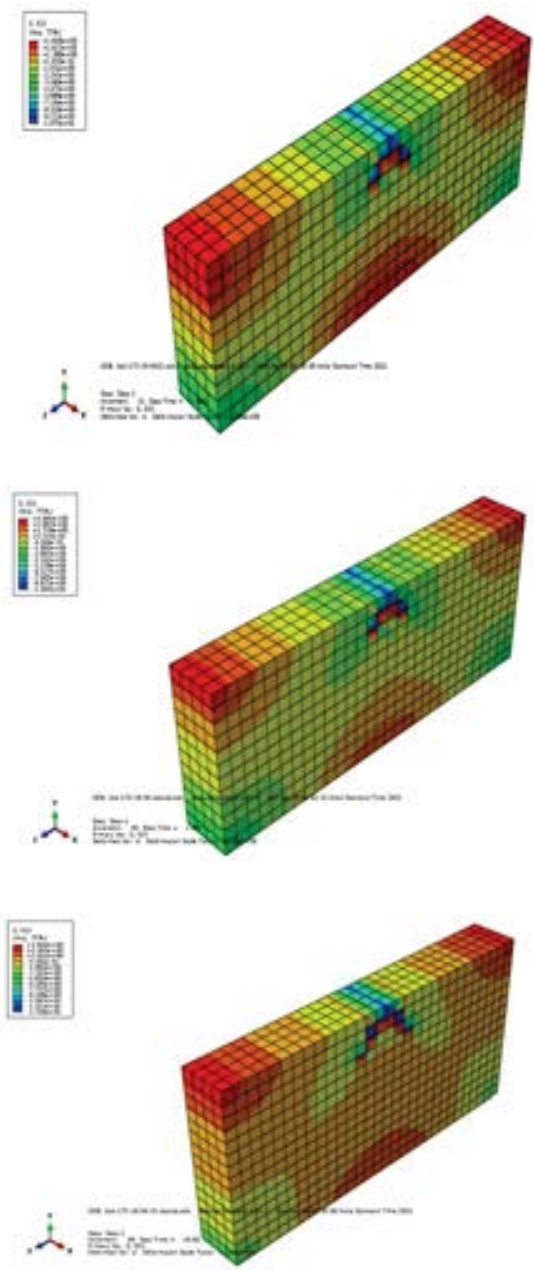

Static loading

Figure 6: Principal stress for RC beams under cyclic and static loading.

B-1
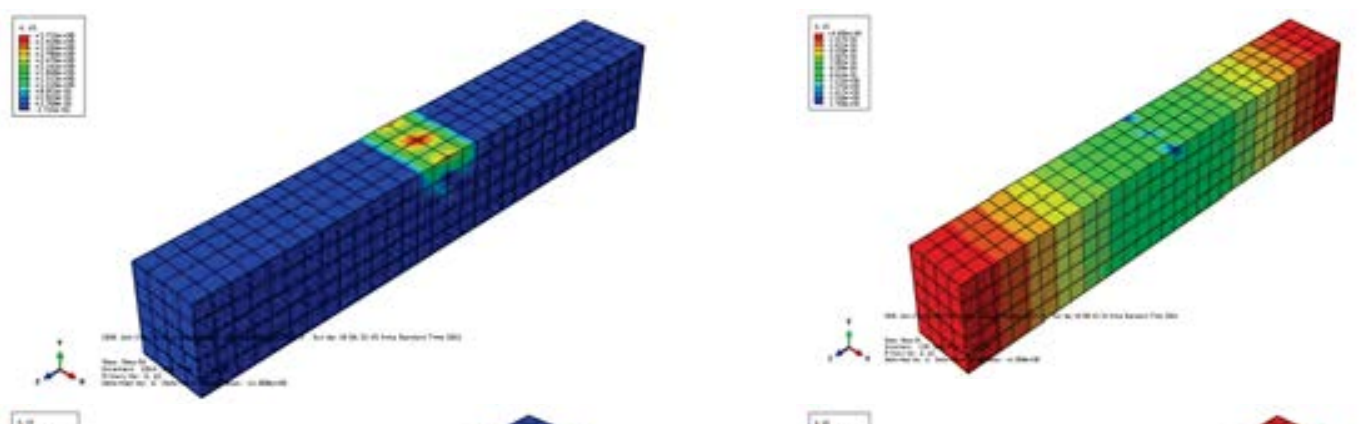

B-2
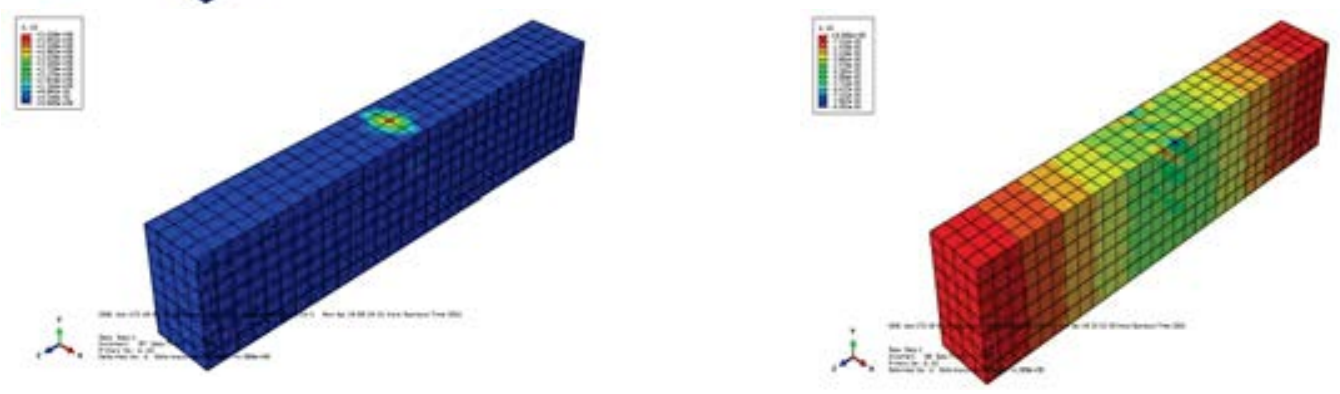


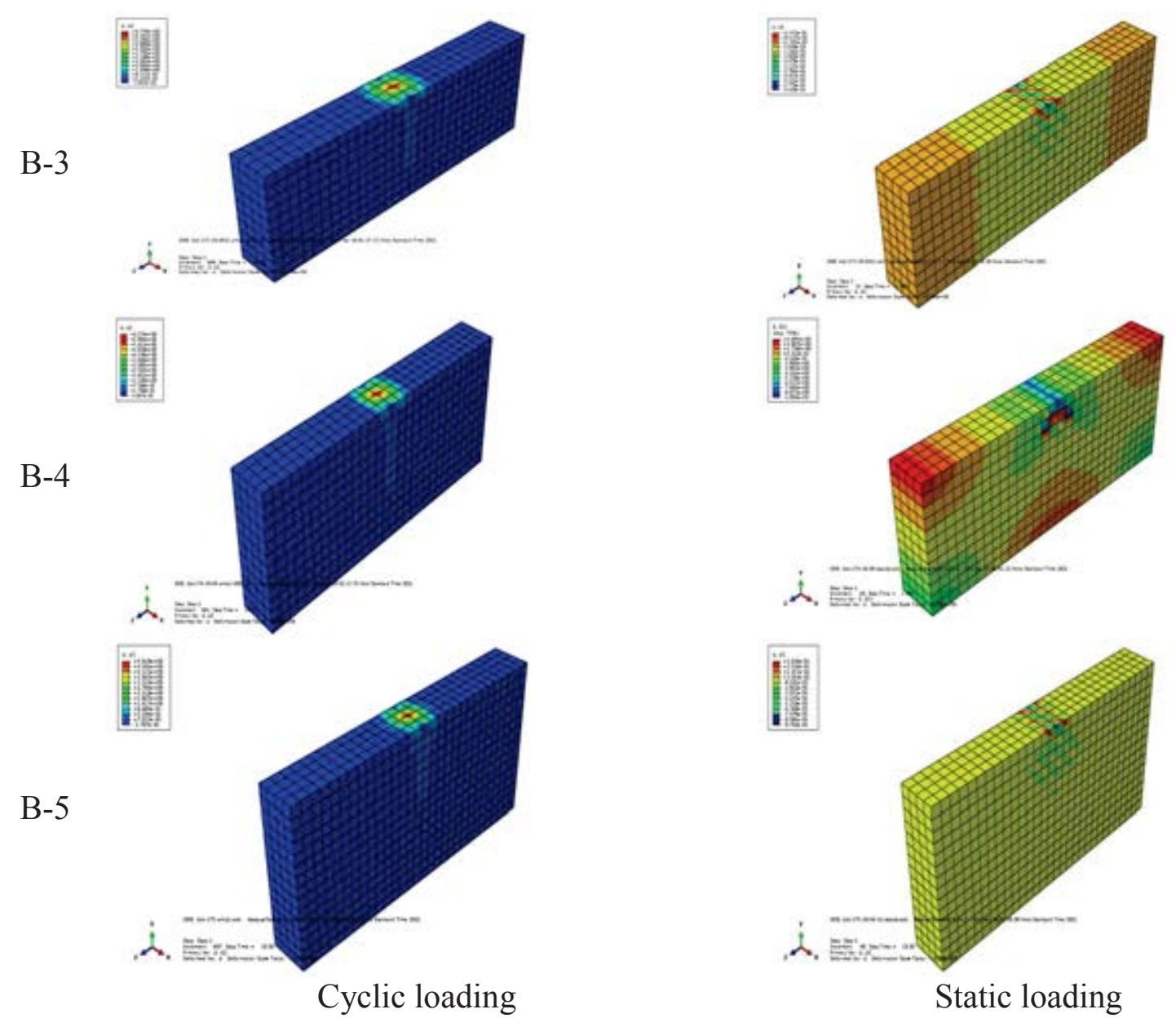

Figure 7: Mid span deflection for RC beams under cyclic and static loading.

Figures 5, 6 and 7 shows the plastic strain, principal stress and mid span deflection for RC beams under cyclic and static loading, respectively. The plastic strain, principal stress and deflection are observed less in the case of B-5 RC beam having a depth of $750 \mathrm{~mm}$ for cyclic load and static load.

\section{CONCLUSIONS}

In the present study, the flexural performance of three-dimensional nonlinear RC beams under cyclic and static loading are analyzed using concrete damaged-plasticity (CDP) model. A parametric study of five different depths of rectangular beams (having width $200 \mathrm{~mm}$ and length $1500 \mathrm{~mm}$ constant) varying from 250 to $750 \mathrm{~mm}$ under static and cyclic loading is carried out. The effect of increasing depth of beam on load-deflection curve of RC beams under cyclic loading and also compared it with static loading are studied. The plastic strain, principal stress and mid span deflection under cyclic and static loadings are investigated. On the basis of FE analysis of RC beams the following conclusions are drawn:

(i) By increasing the depth of beam that is width to depth ratio the load carrying capacity of beam increases for both cyclic and static loadings.

(ii) In cyclic loading it is observed that as the load amplitude is high the damage observed is more as compared to static loading. 


\section{REFERENCES}

[1] T. Yonezawa, H. Shimanuki, and T. Mori, Influence of cyclic loading on the relaxation behavior of compressive residual stress induced by UIT. Welding in the World, 64(1), 171-178, 2020.

[2] A. Abdulrahman Ftaikhan, F. Hejazi, R.S.M. Rashid, and N. Ostovar, Performance of reinforced-concrete frame with embedded FRP rod. IOP Conf. Ser. Earth Environ. Sci., 357, no. 1, 2019.

[3] S. Tsutsumi, R. Fincato, and H. Momii, Effect of tangential plasticity on structural response under non-proportional cyclic loading. Acta Mech., 58(10), 8-19, 2019.

[4] A. Jamadin, Z. Ibrahim, M. Z. Jumaat and E.S.A. Wahab, Effect of high-cyclic loads on dynamic response of reinforced concrete slabs. KSCE Journal of Civil Engineering, 23(3), 1293-301, 2019.

[5] I. S. Koltsida, A. K. Tomor, and C. A. Booth, Strain evolution of brick masonry under cyclic compressive loading. Mater. Struct. Constr., 52(4), 2019.

[6] I. Haris and Z. Roszevàk, Finite element analysis of cast-in-situ RC frame corner joints under quasi-static and cyclic loading. Rev. la Constr., 18(3), 579-594, 2019.

[7] S. Xiao, J. Li, and Y. L. Mo, Effect of loading rate on cyclic behavior of reinforced concrete beams. Adv. Struct. Eng., 21(7), 990-1001, 2018.

[8] I. S. I. Harba and A. J. Abdulridha, Finite element analysis of RC tapered beams under cyclic loading. Al-Nahrain J. Eng. Sci., 20(2), 378-396, 2017.

[9] A. Parvez and S. J. Foster, Fatigue behavior of steel-fiber-reinforced concrete beams. J. Struct. Eng., 141(4), 04014117-01, 2015.

[10] Ł. Polus, and M. Szumigała, Laboratory tests vs. FE analysis of concrete cylinders subjected to compression. AIP Conference Proceedings, 2078, 2019.

[11] ABAQUS Version 6.14 Documentation- ABAQUS Theory Guide, Dassault Systems Simulia Corporation, 2014. 